\title{
Planning and Implementation of the Process Aimed at Teaching English to Adult Learners
}

\author{
Gavriil A. Nizkodubov \\ Associate professor, Ph.D., Tomsk polytechnic university, 634034, Lenina 30, Tomsk, Russia \\ Email:mnusa@yandex.ru \\ Arina M. Evseeva \\ Assistant professor, Tomsk polytechnic university, 634034, Lenina 30, Tomsk, Russia \\ Email: arevseeva@yandex.ru
}

Doi:10.5901/mjss.2015.v6n2p643

\begin{abstract}
The paper deals with a compositional analysis of the adult educator and the adult learner activities intended for acquisition of the English language. Such activities as planning and implementation have been chosen among the others since their role in teaching adult learners is often underestimated despite that adult learners are willing to actively participate in all planning activities related to their own education and they can contribute a lot to the learning process. Participation of adult learners in planning is of paramount importance because adult learners have individual educational needs, their personal experience and level of competence are exceptionally diverse, the social-psychological factors and conditions of learning (time, spatial, life, social) are different compared to school-aged learners. Therefore, their social and professional experience must be taken into account throughout the educational process. In the article, the principles of education for adult learners have been revealed. It has become common knowledge that adult learners are independent, self-directed; they bring experiences and self-awareness to learning, accumulate social and professional experience, they are internally motivated and self-directed, their motivation is determined by aspiration for solving vital problems and achieving particular goals by means of learning. Thus, the adult educator must be aware of the principles before he/she turns to planning and implementation stages.
\end{abstract}

Keywords: learning process, planning, implementation, adult educator, adult learner, principles of adult education.

\section{Introduction}

Generally, planning involves the creation and maintenance of a plan. As such, planning is a fundamental property of intelligent behavior. This thought process is essential to the creation and refinement of a plan, or integration of it with other plans; that is, it combines forecasting of developments with the preparation of scenarios of how to react to them.

An important, albeit often ignored aspect of planning, is the relationship it holds with forecasting (Zmeev, 2007; Kalinin, 2006). Forecasting can be described as predicting what the future will look like, whereas planning predicts what the future should look like.

Planning, as well as forecasting, are the most important parts of the learning process. When teaching young learners the planning stage is minimized as the educator is involved in preparation of a particular lesson. The main objective of the teacher of young learners is to transfer the educational material to the majority of learners that allows them to acquire approximately the same volume of material to achieve the equal level of competence necessary for their "adult" life. Due to the lack of personal experience and a certain level of self-awareness of real-life tasks or problems necessary to solve by means of learning, the young learners cannot participate actively in planning their own learning.

The major difference between the planning of adult teaching and the corresponding stage of the pedagogical teaching model is that the adult learner is trained in all procedures of the stage, and he/she takes an active part in them (Knoweles, 1980; Brookfield, 1986).

It is necessary to plan the learning process for every adult learner because his/her educational needs are individual. Moreover, adult learners have their own life experiences and level of competence. The social and psychological factors are different as well as the learning conditions such as spatial, time, social, life conditions. Thus, a traditional approach to teaching adults is considered to be unacceptable; and planning of the learning process should be made individually for every learner. 
The participation of the adult learner in the process of planning his/her learning is of major importance. In fact, the qualities that an adult has, such as personal experience, self-concept, level of competence, responsibility towards the work, allow him to participate actively in the organization of the learning process.

The specific nature of adult education is revealed in special implementation of the learning process.

Generally, implementation is the realization of an application, or execution of a plan, idea, model, design, specification, standard, algorithm, or policy. Implementation is defined as a specified set of activities designed to put into practice an activity or program of known dimensions. According to this definition, implementation processes are purposeful and are described in sufficient detail such that independent observers can detect the presence and strength of the "specific set of activities" related to implementation. In addition, the activity or program being implemented is described in sufficient detail so that independent observers can detect its presence and strength.

The research aimed at finding out whether adult learners are satisfied with education, shows the most common cause of their discontent: lack of planning involved in adult learning process that affects the implementation of various learning activities afterwards. As a rule, without planning, there will be no mission statement and no vision. Adult learners are most productive when they understand the bigger picture behind what they are doing, so productivity will decrease. There is also likely to be much wasted time, as some learners will be duplicating the work of others, while some essential tasks will be overlooked. This is all likely to result in the need for crisis management. Learners will spend a great deal of time completing tasks caused by the fact that no one is able to anticipate the problems that will regularly occur. In addition, tasks completion will take longer than necessary, or may never reach completion, because the adult learner did not plan his/her class thoroughly. When learners are aware of their disorganized environment, they suffer stress and frustration because they have difficulty executing their assigned tasks. Therefore, planning and implementation of teaching English to adult learners acquires a key significance.

The goals of the research are:

A) to determine the objectives of planning adult learners education;

B) to consider the principles of adult learners education;

C) to analyze the main activities of the educator and learners implemented in the learning process.

\section{Discussion}

Planning of the adult learners education process involves the following conditions: firstly, all procedures of the given stage are implemented, as a rule, by training every learner; secondly, learners participate actively in all procedures of the stage. Planning of the learning process for every particular learner is necessary due to the fact that the adult learners have individual educational needs, their personal experience and level of competence are exceptionally diverse, the social-psychological factors and conditions of learning (time, spatial, life, social) are different (Hanson, 1996; Humphries, 1988; Merriam \& Caffarella, 1991). Therefore, a traditional approach to adult education is inadequate, and the learning process should be planned individually for every learner.

The involvement of the adult learner in planning his/her own learning is feasible and important as an adult has all necessary qualities (self-awareness, personal experience, a certain level of competence, responsible attitude to work) in order to participate in the organization of the learning process as well as the educator.

The following objectives can be pointed out when planning the learning process:

1) Understanding of the learning process by its participants - educator and learners; formation of a clear idea about it both as a whole and its stages and procedures. Perception of the whole learning process is the base of the andragogical approach to its organization. It allows learners and educator to understand their tasks, actions and results to aspire to and contributes to better control of implementing the learning process.

2) Raising responsibility of learners and educators for the organization, implementation and results of the learning process. It is noticed that a person is more engaged in the activity if he/she has taken part in its planning. Therefore, the involvement of the learner in planning his/her own learning raises considerably his/her responsibility for its organization, implementation and results.

3) Increasing of the adult learner motivation. Involvement in planning, understanding of the learning process, high responsibility for its results makes the adult learner more motivated (Knoweles, 1980).

Thus, there are the following peculiarities and objectives of planning the adult education process: firstly, the adult learners take an active part in planning, and secondly, the planning stage has the individual value, it proposes the individual approach to every learner, and takes enough long time.

The planning of teaching a foreign language is based on certain principles. They are required for determining the strategy and tactics of learning as they are related to planning, content, methods, techniques, organization of education; 
and they are interrelated.

The fundamental principles of adult education can be considered in theory that helps gain insight into each of them, and in practice for using them as the rules, requirements, and recommendations while learning.

The education principles focused on the practical use of the English language are of the utmost interest as in adult education the very practical use of the language is important.

The adult learner has certain characteristics. He/she has an independent, self-directed personality; accumulates the experience (life, professional, social experience); aims at the immediate application of knowledge and skills; his/her learning activity is determined significantly by the time, spatial, life, professional and social factors; his/her readiness to learn (motivation) is determined by aspiration for solving vital problems and achieving particular goals by means of learning.

Based on the given assumptions the following principles of adult education can be pointed out:

A) Teamwork between the educator and adult learner and other learners at all stages of education: while planning, implementing, evaluating and correcting. The learner has a leading role in the learning process because he/she participates actively in it.

B) The priority of the self-directed learning (autonomy). The learner's self-directedness assumes that he/she acts in accordance with his/her own goals and needs, solving a communication problem, and makes decisions without the external control. The self-directed activity is understood not only as independent learning as the type of academic activity, but also as the learner's self-directedness in the organization of his/her learning. The learners' activity is specified by a learner-centered approach that involves subject-subject relationships. The learner is no longer the object of learning; he/she becomes the subject of the learning process. The educator contributes to the development of learners' intellectual work resulting in formation of creative personality - the adult learner aspires to self-fulfillment, self-directedness and self-management.

C) Orientation to the learners' experience. According to this provision the personal, life, social, professional experience of the learners is used as one of the the educational resources of the learner himself as well as other learners.

D) Personalized learning. In adult education, it is necessary to consider the particular educational needs and learning objectives, the competence level and cognitive characteristics of the learners.

E) Modular structure. Reliance on this provision enables flexible and rapid creation of learning models that can be as close as possible to the needs of specific categories of the individuals in the framework of the adult education. Implementation of this principle also creates a sort of flexibility to rebuild the learning model in the educational process in response to the changing needs of adult learners.

F) Learning outcomes. This provision requires an immediate practical application of acquired knowledge, skills and abilities - one of the ways of preservation and development of high motivation to learning.

G) Elective courses. This provision provides the adult learner with a certain freedom of choice of objectives, content, forms, methods, sources, time, training, assessment of learning outcomes.

H) Development of educational needs. Firstly, this provision involves evaluation of the learning outcomes that is performed by identifying the real extent of development of educational material and identifying those materials without the assimilation of which it is impossible to achieve learning objectives. Secondly, the learning process is built for the development of new educational learners' needs, specification of which is carried out after accomplishment of certain learning objectives.

I) Learning awareness. Adult learners and the adult educator are aware of all the parameters of the learning process and their actions must be applied to its planning and arrangement.

Thus, education arrangement, in view of the provisions that have been already set forth above, contributes to the formation and improvement of skills to search for solutions, choose the best solutions to the educational problems and implement them. Therefore, existing knowledge and experience in a new environment must be activated in the classroom. Students learn to predict and to draw conclusions based on logical reasoning. Learning tasks, that require learning and processing large amounts of textual material, stimulate their cognitive activity.

Fundamental provisions of adult learning activities define the activities of the adult learner and the adult educator in the learning process. Adult learner activities aimed for implementation of the learning process lie primarily in the fact that the adult educator plans and arranges interaction of all participants in the learning process, drives potential relationships between: himself/herself, adult learners, content, sources and means, forms and methods of teaching.

In the framework of adult education it is required to conduct rapid psycho-physiological, psychosocial and cognitive diagnosis of adult learners to identify their willingness to be included in the process of learning in a particular class. Adult learners attend classes with a different mood, various conditions of physical health and sanity, fatigue, often burdened 
with household, professional, and social problems. With aging, the influence of these factors increases and these various conditions must be considered while teaching adult learners.

In each particular class, the adult educator should identify real educational tasks in accordance with the level of students' preparedness to be included in the learning process. In other words, the adult educator should either try to achieve the required level of students readiness to learn, or, depending on their condition, determine the exact amount of the material being studied and appropriate forms as well as teaching methods.

Thus, learning activities of the adult educator in the implementation phase consist in the completion of the study program that has been previously planned and arranged together with adult learners. Activities of the adult educator in the implementation phase of the learning process aim at flexible building of a learning process based on the data line diagnostics of learners in order to achieve optimal progress towards the learning objectives which have been set at the planning stage.

At the stage of technical actions the adult educator performs special actions for the implementation of the above mentioned operations, conducts diagnostic survey, a brief interview with learners, and observes their reaction and behavior to determine their willingness to learn. In cooperation with learners, the adult educator identifies specific learning objectives, creates a learning situation where the joint activities of all the participants and members of the learning process are implemented.

The adult educator, depending on the learning goals and objectives of a particular class, as well as the characteristics and readiness of learners to be included in the learning process, implements appropriate sources, tools, forms and teaching methods. The right choice of forms and teaching methods is essential at this stage. The adult educator creates problem situations, implements heuristics, research, design (introduces joint projects or develops a common problem) teaching methods that would allow adult learners, based on their life experience and previous training, come to certain conclusions by summarizing the facts and observations, find certain patterns and true solutions to the learning problems.

The same can be stated with regard to forms of training. An important factor in the choice of adequate methods and forms of learning is a learning objective. M.S. Knowles identified six "super objectives": knowledge acquisition, awareness attainment, clarification (data generalization and application in practice); acquisition of skills, qualities and values. The scientist believes that in order to achieve these common objectives the following teaching forms must be used respectively: lectures, broadcasts, discussions, dialogues, interviews, workshops, group interviews, colloquiums, film strips, slides, sound recordings, reading, after reading discussions; participation in discussions, demonstration (experiments, etc.), dramatization, discussions, problem discussions, discussions of specific cases, critical analysis; role play, case studies, group trainings, experiments, practice etc.

Thus, the technical steps of the adult learner during the implementation phase of the learning process are independent search and the use of various sources, means, forms and methods of teaching aimed at completion of the individual training courses arranged in cooperation with the adult educator. In such case, the adult learner must consult with the adult educator on the use of adequate sources, means, forms and methods of training.

\section{Methodology}

This research synthesis was conducted with the aim of identifying those adult learning method characteristics that could be used to inform changes and improvements in planning and training opportunities. The findings clearly have direct implications for this purpose. The results also have implications for other kinds of instruction with adults. The implications for training include the following:

- The adult learning method characteristics constituting the focus of investigation provide guidance and structure for developing effective training and technical assistance programs and practices. The most effective training is likely to include learner experiences and opportunities in each of the three main components of adult learning (planning, application, and deep understanding).

- The more adult learning method characteristics that are incorporated into a training program or practice, the more likely the learning experiences will have optimal positive benefits: a different vantage point for promoting learner acquisition, use, and evaluation of new knowledge, material, or practice.

- The common element of adult learning methods that are most effective is active learner participation in the learning process. This is consistent with both the basic tenets of adult learning theory as well as research showing that active participation in learning

- Training opportunities are likely to be most effective if they include multiple learning experiences, large doses of learner self-assessment of their experiences, and instructor facilitated learner assessment of his or her 
learning against some set of standards or criteria. The more opportunities a learner has to acquire and use new knowledge or practice, the more frequently those opportunities occur, and the more the learner is engaged in reflection on those opportunities using some external set of standards, the greater the likelihood of optimal benefits.

\section{Conclusion}

To summarize, it should be noted that:

A) By identifying planning objectives in the process of adult education, we come to the conclusion that adult learners take an active part in the planning stage, the planning stage is of great independent significance, it suggests an individual approach to each learner and takes quite a long time in the education process;

B) By discussing education principles of adult learners, we highlight such principles as: teamwork activities, selfdirected learning (education autonomy), relying on the experience of the learner, personalized learning, modular construction, learning outcomes, elective courses, development of educational needs, learning awareness;

C) Having analyzed main activities of the adult educator and the adult learner in the learning process, we conclude that the main activity of the adult learner at this stage is to complete the education program which has been previously planned and arranged together with the adult educator, the technical steps of the adult learner during the implementation phase of the learning process are independent search and use of various source, means, forms and methods of teaching aimed at completion of the individual training courses arranged in cooperation with the adult educator.

\section{References}

Zmeev S.I. (2007). Andragogy: Basic theory, history and technology of adult learning. Publishing house: PER SE.

Kalinin A.G. (2006). Individual-based model of organizing additional adult education in foreign languages (based on English): Dis.PhD. Ped. Sciences. Nizhny Novgorod.

Gromkova M.T. (2005). Andragogy. Theory and practice of adult education. Moscow, Publishing House: "Unity-Dan".

Knowles M.S. (1980). The modern practice of adult education: From pedagogy to andragogy. Chicago, IL: Association Press/Follet.

Brookfield, S. D. (1986) Understanding and facilitating adult learning. A comprehensive analysis of principles and effective practice, Milton Keynes: Open University Press.

Hanson, A. (1996) 'The search for separate theories of adult learning: does anyone really need andragogy?' in Edwards, R., Hanson, A., and Raggatt, P. (eds.) Boundaries of Adult Learning. Adult Learners, Education and Training Vol. 1, London: Routledge.

Humphries, B. (1988) 'Adult learning in social work education: towards liberation or domestication'. Critical Social Policy No. 23, 4-21.

Merriam, S. B. and Caffarella, R. S. (1991) Learning in adulthood. A comprehensive guide, San Francisco: Jossey-Bass. 